\title{
Firing Control Optimization of Impulse Thrusters for Trajectory Correction Projectiles
}

\author{
Min Gao, Yongwei Zhang, and Suochang Yang \\ Electronic Engineering Department, Shijiazhuang Mechanical Engineering College, No. 97 Heping West Road, \\ Shijiazhuang, Hebei 050003, China \\ Correspondence should be addressed to Yongwei Zhang; yongweil112@sina.com
}

Received 12 February 2015; Revised 7 April 2015; Accepted 13 April 2015

Academic Editor: Paul Williams

Copyright (C) 2015 Min Gao et al. This is an open access article distributed under the Creative Commons Attribution License, which permits unrestricted use, distribution, and reproduction in any medium, provided the original work is properly cited.

This paper presents an optimum control scheme of firing time and firing phase angle by taking impact point deviation as optimum objective function which takes account of the difference of longitudinal and horizontal correction efficiency, firing delay, roll rate, flight stability, and so forth. Simulations indicate that this control scheme can assure lateral impulse thrusters are activated at time and phase angle when the correction efficiency is higher. Further simulations show that the impact point dispersion is mainly influenced by the total impulse deployed, and the impulse, number, and firing interval need to be optimized to reduce the impact point dispersion of rockets. Live firing experiments with two trajectory correction rockets indicate that the firing control scheme works effectively.

\section{Introduction}

Dispersion characteristics of the trajectory correction projectiles can be dramatically improved by outfitting with a suitable trajectory correction flight control system. The commonly used executive organs are moveable canards [1$3]$, fixed canards $[4,5]$, synthetic jets [6], drag brakes $[7,8]$, and impulse thrusters [9-21].

The work reported here describes the implementation of a flight control system with impulse thrusters on a representative $122 \mathrm{~mm}$ artillery rocket. The flight control consists of a finite number of impulse thrusters mounted forward on the rocket body, computes position and velocity errors through comparing the position and velocity measured by GPS with prespecified (reference) trajectory, fires thrusters to change velocity direction, and assists the rocket to follow a prespecified trajectory.

Research and development on the use of impulse thrusters in order to improve the precision of projectiles has been going on for decades. Brandeis and Gill [9] have studied the effect of the impulse thruster on the forces and moments and investigated the impact of size and location of planar surfaces on the amplification of the impulse thruster. Burchett et al. [10] developed a simple set of formulae for the swerve motion of a dual-spin projectile under the action of lateral pulse jets and pointed out that the ability of lateral pulse jets to change the impact point steadily decreases with range to the target. Corriveau et al. [11] described a novel method for correcting the trajectory of spin- and fin-stabilized projectiles using pairs of impulse thrusters located away from the center of mass; they used the linear theory of ballistics to develop an analytical model representing the motion of a projectile subjected to impulse thrusters.

The thrusters' application on rockets has been originally considered by Harkins and Brown [12]. They have proposed a method using a set of impulse thrusters to marginalize the off-axis angular rates of the rockets just after exiting the launcher and managed to reduce the impact point dispersion by the factor of 4 . Jitpraphai and Costello [13] have proposed a simplified control system with impulse thrusters and demonstrated that impact point dispersion of a direct fire rocket could be drastically reduced. Burchett and Costello [14] have investigated the use of a small number of shortduration lateral pulses acting as a control mechanism to reduce the dispersion of a direct fire rocket and studied the effect of the number and amplitude of individual pulse jets. Gupta et al. [15] have explored the feasibility of reducing the impact point dispersion of a routinely used artillery rocket 


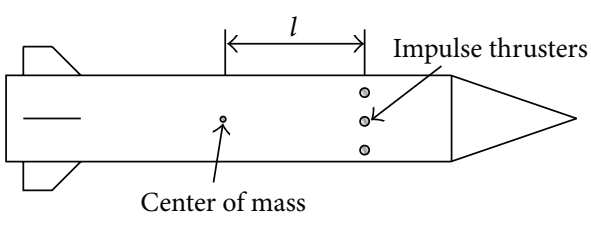

(a) Layout of thrusters

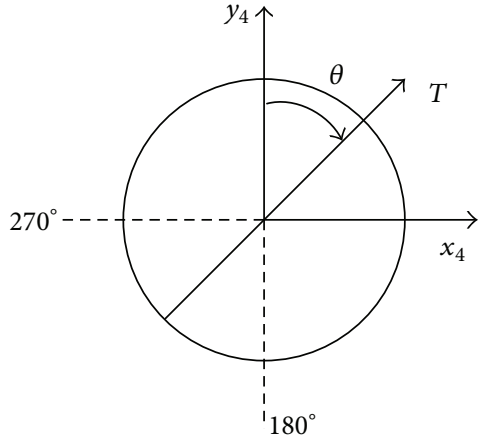

(b) Lateral force

FIgURE 1: Schematic of layout and lateral force of thrusters.

using lateral pulsejets coupled to a trajectory correction flight control system. Pavkovic et al. [16] have presented a new two-phase guidance scheme named trajectory tracking with pulse-frequency modulation which is presented, considering the fact that an artillery rocket flies through different atmospheric environments; the presented guidance scheme achieves excellent accuracy even in the case of a small number of pulse jets. Recently, Pavkovic et al. [17] have presented a simplified control scheme for artillery rockets named the active damping method which performs a correction of disturbances immediately after a rocket exits a launcher tube. It is shown that the application of such a control system achieves a significant dispersion reduction.

Each impulse thruster imparts a single, short-duration, large force to the rocket in the plane normal to the rocket axis of symmetry, the control scheme of impulse thrusters mainly involves two aspects: the firing time and the firing phase angle. Many researchers [13-15] compute firing phase angle by the phase angle of trajectory deviation; theoretical analysis shows that this method may not get the best trajectory correction performance under some conditions, and the induced effects of rocket flight time on trajectory performance are not considered. Yang et al. [18] converts the problem of determining control parameters of the pulsejets into the design of the experiment with multifactor and multilevel. Introducing the firing time as a controllable factor, the relationship model among firing time, number of pulsejets, and total value of trajectory correction was obtained by using regression analysis. This scheme can determine the firing time and number of pulsejets needed quickly and reduce the trajectory error of the rocket effectively, but the difference of longitudinal and horizontal correction efficiency is not considered. Cao et al. [19] present an optimization strategy for the firing phase angle, which makes the total number of thrusters minimized for the residual trajectory deviation after previous correction. However, the foremost goal of trajectory correction is to decrease the trajectory error; the consumption number of thrusters should be taken as the secondary factor.

In this paper, to reduce the impact point dispersion of the trajectory correction rocket using impulse thrusters, a 6-DOF trajectory model with lateral force is established, and then the control algorithm of firing time and firing phase angle is put forward, taking impact point deviation as optimum objective function.

\section{6-DOF Trajectory Model with Lateral Force}

The numerical simulation is based on a rigid body six degrees of freedom model typically utilized in flight dynamic analysis of rockets. Figure 1 shows the rocket configuration with an impulse thruster ring mounted on the forward part of rockets. The thrusters are assumed to be located at $l$ from the center of mass. The 6-DOF trajectory model with lateral force can be established by taking the lateral force and its moment into the ballistic motion equations.

The lateral force in quasibody reference frame can be described as

$$
\left[\begin{array}{c}
T_{x_{4}} \\
T_{y_{4}} \\
T_{z_{4}}
\end{array}\right]=\left[\begin{array}{c}
0 \\
T \cos \theta \\
T \sin \theta
\end{array}\right] .
$$

In (1), $T$ is the lateral force of an impulse thruster in quasibody reference frame, and $\theta$ is the phase angle of lateral force.

Transforming the lateral force from the quasi body to the aeroballistic reference frame, we have

$$
\begin{aligned}
& {\left[\begin{array}{l}
T_{x_{2}} \\
T_{y_{2}} \\
T_{z_{2}}
\end{array}\right]} \\
& =\left[\begin{array}{ccc}
\cos \alpha \cos \beta & -\sin \alpha \cos \beta & \sin \beta \\
\sin \alpha & \cos \alpha & 0 \\
-\cos \alpha \sin \beta & \sin \alpha \sin \beta & \cos \beta
\end{array}\right]\left[\begin{array}{c}
0 \\
T \cos \theta \\
T \sin \theta
\end{array}\right] .
\end{aligned}
$$

In (2), $\alpha$ is the angle of attack of the rocket, and $\beta$ is its sideslip angle. 
The translational kinetic differential equations of the rocket in aero-ballistic reference frame are given in

$$
\begin{aligned}
\frac{d V}{d t} & =P_{x_{2}}+F_{x_{2}}+T_{x_{2}}, \\
V \frac{d \theta^{\prime}}{d t} & =P_{y_{2}}+F_{y_{2}}+T_{y_{2}}, \\
-V \cos \theta^{\prime} \frac{d \psi_{v}}{d t} & =P_{z_{2}}+F_{z_{2}}+T_{z_{2}} .
\end{aligned}
$$

The applied loads appearing in (3) consist of main rocket thrust $(P)$, lateral thruster force $(T)$, and other forces $(F)$ components. $V, \theta^{\prime}$, and $\psi_{v}$ are the velocity, trajectory incline angle, and flight path azimuth angle of the rocket, respectively.

Lateral moment of an impulse thruster in quasibody reference frame is given by

$$
\left[\begin{array}{l}
M_{T x_{4}} \\
M_{T y_{4}} \\
M_{T z_{4}}
\end{array}\right]=\left[\begin{array}{c}
0 \\
-T_{z_{4}} l \\
T_{y_{4}} l
\end{array}\right] .
$$

The rotational kinetic differential equations of the rocket in quasibody reference frame are given by

$$
\begin{aligned}
{\left[\begin{array}{l}
J_{x_{4}} \frac{d \omega_{x_{4}}}{d t} \\
J_{y_{4}} \frac{d \omega_{y_{4}}}{d t} \\
J_{z_{4}} \frac{d \omega_{z_{4}}}{d t}
\end{array}\right]=} & {\left[\begin{array}{l}
M_{x_{4}}+M_{T x_{4}} \\
M_{y_{4}}+M_{T y_{4}} \\
M_{z_{4}}+M_{T z_{4}}
\end{array}\right]-\left[\begin{array}{c}
0 \\
\left(J_{x_{4}}-J_{z_{4}}\right) \omega_{x_{4}} \omega_{z_{4}} \\
\left(J_{y_{4}}-J_{x_{4}}\right) \omega_{x_{4}} \omega_{y_{4}}
\end{array}\right] } \\
& +\left[\begin{array}{c}
0 \\
-J_{z_{4}} \omega_{z_{4}} \frac{d \gamma}{d t} \\
J_{y_{4}} \omega_{y_{4}} \frac{d \gamma}{d t}
\end{array}\right] .
\end{aligned}
$$

The applied moments appearing in (5) contain contributions from lateral thruster forces, denoted by $M_{T}$, and other forces, denoted by M. $\gamma$ is the Euler roll angle of the rocket. $w_{x_{4}}, w_{y_{4}}$, $w_{z_{4}}$ are components of the angular rate vector. $J_{x_{4}}, J_{y_{4}}, J_{z_{4}}$ are components of the transverse moment of inertia.

Other motion equations of the rocket not involving lateral forces or lateral moments can be obtained in [21].

\section{The Establishing of Optimum Objective Function}

Figure 2 shows trajectory correction progress of an impulse thruster. Assuming that $M$ is the target and $O$ is the predicted impact point computed by flight control system, the distance between the predicted impact point and the target is $O M$, and the longitudinal and horizontal deviations are $\Delta L$ and $\Delta H$, respectively. Assuming that the longitudinal and horizontal correction distance of an impulse thruster is $P_{x}$ and $P_{z}$, respectively, if the impulse thruster is activated, the predicted impact point of the rocket will be changed to $A$; then the

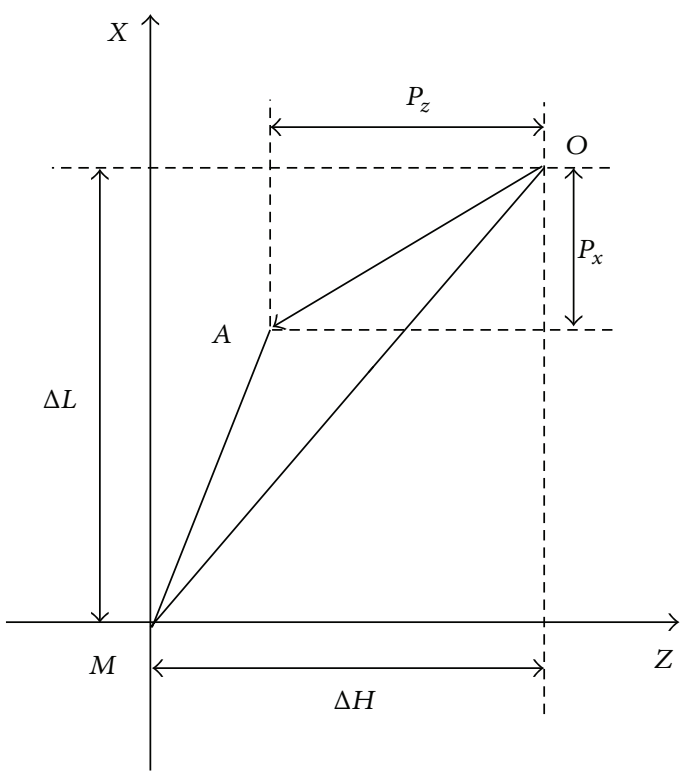

FIGURE 2: Schematic of trajectory correction.

distance between the predicted impact point and the target will be reduced to be $A M$ upon the impact of an impulse thruster.

Because the aim of trajectory correction is to reduce the impact point deviation, it is foremost to make best use of the energy of impulse thrusters to obtain the minimum impact point deviation. Therefore, the remaining impact point deviation after an impulse thruster was activated, namely, $A M$, and is taken as the optimization objective function in this paper. It is assumed that the positive direction of $\Delta L$ and $P_{x}$ is the same, and the positive direction of $\Delta H$ and $P_{z}$ is the same, and then $A M$ can be described by

$$
A M=\left[\left(\Delta L+P_{x}\right)^{2}+\left(\Delta H+P_{z}\right)^{2}\right]^{1 / 2} .
$$

In (6), $\Delta L$ and $\Delta H$ are the longitudinal and horizontal predicted deviation, computed by the flight control system and remain constant during a short time, so the change of $A M$ mainly relates to $P_{x}$ and $P_{z}$ of the impulse thruster activated. $P_{x}$ and $P_{z}$ depend on roll rate of the rocket, impulse, firing time, and firing angle phase of the thruster; individual thruster impulse and roll rate of the rocket have been determined in the design phase of trajectory correction rockets; therefore, the firing time and firing phase angle are taken as optimization variables of the objective function in the flight phase.

\section{Optimization of Firing Phase Angle}

The optimization variables firing time and firing phase angle are relatively independent and assumed that the firing time of an impulse thruster has been identified; then the firing phase angle is the only optimization variable of an impulse thruster. To analyze the impact of firing phase angle on the trajectory correction performance, the lateral force is seen as a constant because the thrusters are active over a very 


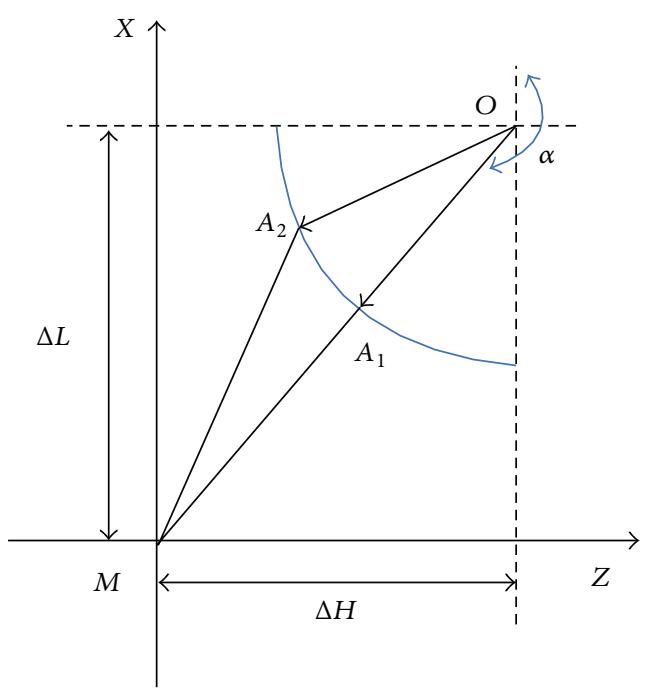

(a) With equal converting coefficients

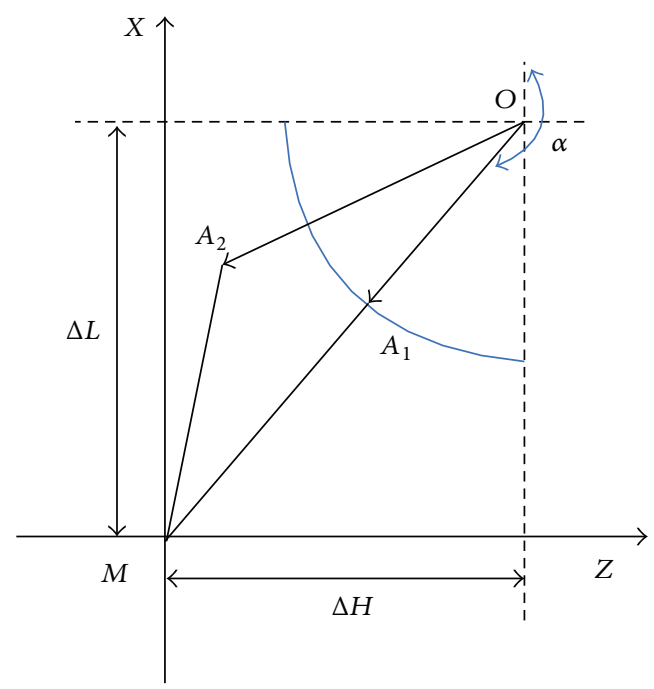

(b) With unequal converting coefficients

FIGURE 3: Trajectory correction performance with equal and unequal converting coefficients.

short duration of time, and $\theta$ denotes the phase angle of lateral force in quasibody reference frame. To get the best trajectory correction performance, the best phase angle of lateral force leads to the minimum value of $A M$, is denoted by $\theta_{m}$, and should be computed firstly. The conventional method to compute $\theta$ is by making its value equal to phase angle of trajectory deviation, denoted by $\alpha$, referencing to Figure 3(a). However, whether or not this method can get the best trajectory correction performance depends on the longitudinal and horizontal correction efficiency (namely, as converting coefficient) of the impulse thrusters.

Given that the correction distance of an impulse thruster is proportional to the thruster impulse, $P_{x}$ and $P_{z}$ can be described by

$$
\begin{aligned}
& P_{x}=k_{x} \cdot \cos \theta, \\
& P_{z}=k_{z} \cdot \sin \theta .
\end{aligned}
$$

In (7), $I$ is the impulse of a thruster. $k_{x}$ and $k_{z}$ are longitudinal and horizontal converting coefficients of an impulse thruster for the rocket. The converting coefficients reflect the correction efficiency of the impulse thruster. The impact of correction efficiency on the objective function will be analyzed under two conditions.

(1) When $k_{x}=k_{z}$, longitudinal and horizontal correction efficiency of an impulse thruster is the same and assumed that $O$ is the predicted impact point of the rocket; then possible impact points after correction of an impulse thruster form a circle around $O$. Assuming that the correction distances are $O A_{1}$ and $O A_{2}$, corresponding to $\theta=\alpha$ and $\theta \neq \alpha$, then $O A_{1}=O A_{2}$, and $O A_{1}$ has the same direction with $O M$, referring to Figure 3(a). The following equation can be obtained according to triangle trilateral theorem:

$$
O A_{1}+A_{1} M<O A_{2}+A_{2} M
$$

Because $O A_{1}=O A_{2}, A_{1} M<A_{2} M$. Therefore, when $k_{x}=$ $k_{z}$, objective function $A M$ can get the minimum value with $\theta=\alpha$.

(2) When $k_{x} \neq k_{z}$, longitudinal and horizontal correction efficiency of an impulse thruster is different, whether or not $O A_{1}=O A_{2}$ is not certain and, referring to Figure 3(b), $A_{1} M$ may be bigger than $A_{2} M$, so objective function cannot always get the minimum value with $\theta=\alpha$. Under this condition, a new method is required to compute $\theta_{m}$.

In fact, $k_{x} \neq k_{z}$ in most of the flight time, as shown in Figure 6, a new method to compute best phase angle of lateral force is proposed in this paper. Because an analytic solution is not acquired by (6), $\theta_{m}$ is solved by the binary iteration method given in Figure 4 , where $\left[\theta_{1}, \theta_{2}\right]$ is the solution limits and $N$ is the number of iterations.

To reduce the number of iterations and improve the solution accuracy, solution limits can be acquired by (9).

The solution accuracy can reach $0.1 \mathrm{deg}$ with $N=10$, so $\theta_{m}$ can be solved quickly by this method.

The firing phase angle, denoted by $\Phi_{c}$, is the phase angle of the impulse thruster in quasibody reference frame when it gets the firing signal from the flight control system. Firing time delay and impulse duration time should be taken into account to make sure the average angle of lateral force is equal to $\theta_{m}$ :

$$
\left[\theta_{1}, \theta_{2}\right]= \begin{cases}{\left[0^{\circ}, 90^{\circ}\right]} & \Delta H<0, \Delta L<0 \\ {\left[90^{\circ}, 180^{\circ}\right]} & \Delta H<0, \Delta L>0 \\ {\left[180^{\circ}, 270^{\circ}\right]} & \Delta H>0, \Delta L>0 \\ {\left[270^{\circ}, 360^{\circ}\right]} & \Delta H>0, \Delta L<0 .\end{cases}
$$

Schematic of firing phase angle is given in Figure 5. The relation between firing phase angle $\Phi_{c}$ and $\theta_{m}$ is given by

$$
\Phi_{c}=\theta_{m}+\pi-\omega\left(\tau_{d}+\tau\right) .
$$




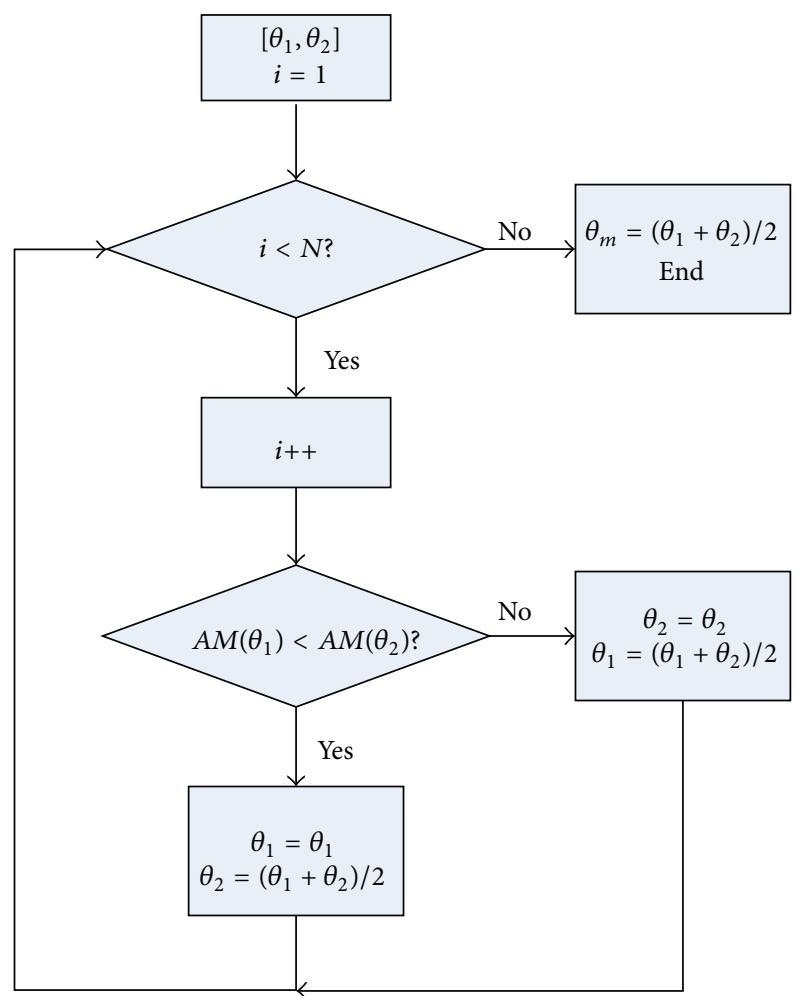

FigUre 4: Solution flow of $\theta_{m}$.

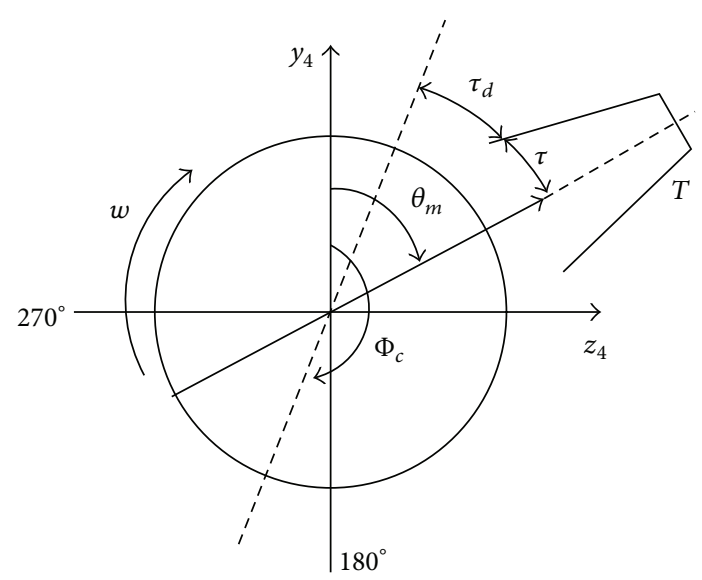

FIGURE 5: Schematic of firing phase angle.

In (10), $\tau_{d}$ is the firing delay, and $\tau$ is a half of the impulse duration. $\omega$ is the roll angular rate of rocket.

When the phase angle $\Phi$ of the impulse thruster that will be activated is equal to the firing phase angle, the impulse thruster can be activated; the condition to activate an impulse thruster is

$$
\left|\Phi-\Phi_{c}\right| \leq \varepsilon
$$

In (11), $\varepsilon$ is the desired activation threshold.

\section{Optimization of Firing Time}

After the optimization of firing phase angle, the other optimization variable of objective function is the firing time of thrusters. The general firing time control algorithm has two strategies.

(1) Time elapsed from the previous impulse thruster firing must be longer than a specified time duration $\Delta t_{\text {fire }}$ :

$$
t-t^{*}>\Delta t_{\text {fire }}
$$

In (12), $t^{*}$ is the firing time of the previous impulse thruster.

(2) If predicted impact point deviation is greater than a specified distance, activate the thruster as soon as possible.

$\Delta t_{\text {fire }}$ is an important design parameter of thrusters. If it is set too low, the rocket does not have sufficient time to respond and too many thrusters will be fired, tending to overcompensate for trajectory deviation. Simultaneously, a lower $\Delta t_{\text {fire }}$ may have an impact on the flight stability of the rocket. On the other hand, if it is set too high, only a small number of thrusters can possibly be fired and the capabilities of the residual impulse thrusters will be wasted.

The impact of flight time on trajectory correction performance of thrusters is not considered by strategy (2), which may lead to the thrusters being activated at the time when the correction efficiency is lower. Gao and Zhang [20] gave the conclusion that the longitudinal correction efficiency of thrusters is lower in ballistic ascending segment of the rocket, and longitudinal and horizontal correction efficiency reduces with the decrease of time to go in ballistic descending segment. Simulation results of converting coefficients of a rocket are shown in Figure 6, the launch angle of the rocket is $45 \mathrm{deg}$, and the impact angle is $-64 \mathrm{deg}$.

As shown in Figure $6, k_{x}$ and $k_{z}$ have different change trends, and $k_{x}$ increases gradually in ballistic ascending segment and decreases gradually in ballistic descending segment, while the $k_{z}$ decreases gradually with the decrease of time to go. The behavior of $k_{x}$ and $k_{z}$ has a physical reason. According to the kinetic energy theorem, the rocket will get a velocity increment $\Delta V$ when an impulse thruster was activated, the direction of $\Delta V$ is nearly perpendicular to the velocity direction of rocket. When an impulse thruster was activated for longitudinal correction, $\Delta V$ can be decomposed into $\Delta V_{x}$ and $\Delta V_{z}$, as shown in Figure 7; supposing that the lateral force of the impulse thruster is upward, then $\Delta V_{y}=$ $\Delta V \cos \left(\theta^{\prime}\right)$, and $\Delta V_{x}=-\Delta V \sin \left(\theta^{\prime}\right)$, where $\theta^{\prime}$ denotes the trajectory incline angle. In ballistic ascending segment, $\theta^{\prime}>0$, so $\Delta V_{x}<0$, which will shorten the rocket range, while $\Delta V_{y}>$ 0 , which will extend the rocket range, the impact of $\Delta V_{x}$ and $\Delta V_{y}$ is contradictory, and, therefore, the impact of $\Delta V$ is relatively small at the beginning of ballistic descending segment. As the trajectory inclination angle ranges from $45 \mathrm{deg}$ to $0 \mathrm{deg}$, the absolute value of $\Delta V_{y}$ increases gradually, while the absolute value of $\Delta V_{x}$ decreases gradually; as a result, the longitudinal correction distance of a thruster increases gradually in ballistic ascending segment. In ballistic descending segment, trajectory inclination angle ranges from $0 \mathrm{deg}$ to -64 deg, so $\Delta V_{x}>0$, which will extend the rocket range, and $\Delta V_{y}>0$, which will also extend the rocket range; the longitudinal correction distance is mainly influenced by the time to go; therefore, longitudinal correction distance of a thruster decreases gradually with the decrease of time to go in ballistic descending segment. In the horizontal plane, $\Delta V_{z} \approx \Delta V$, 


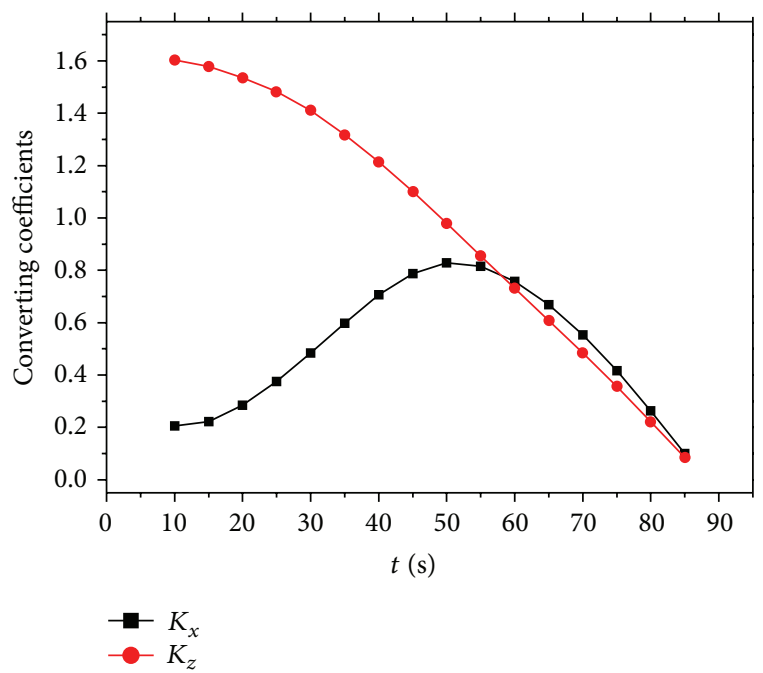

FIGURE 6: Converting coefficients versus flight time.

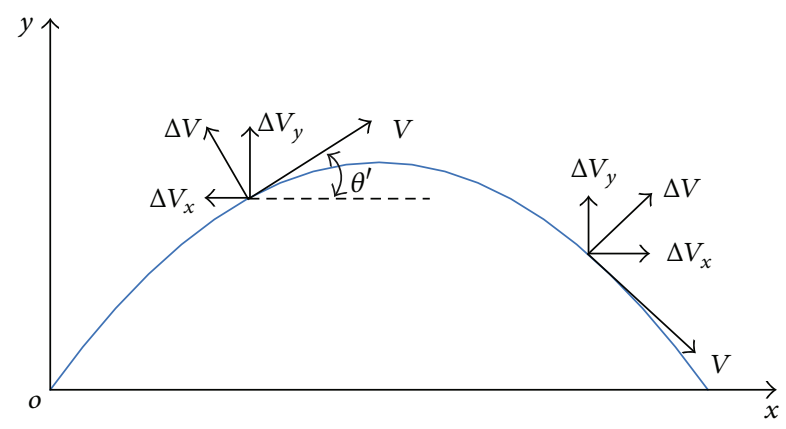

FIGURE 7: Schematic of velocity increment of a thruster.

the horizontal correction distance is mainly influenced by the time to go, and hence the horizontal correction distance decreases gradually with the decrease of time to go. Therefore, $k_{x}$ and $k_{z}$ have the change trends shown in Figure 6.

It can be known from (6) and Figure 6 that the value of the objective function (activated at the optimized firing phase angle) tends to increase in ballistic descending segment. Supposing that $t_{k}$ is the time of ballistic vertex, the value of the objective function at $t_{k}$ can be taken as a reference value, denoted by $A M\left(t_{k}\right)$. In ballistic ascending segment, thrusters can be activated if the value of the objective function is less than the reference value $A M\left(t_{k}\right)$, otherwise they cannot. This method can guarantee that thrusters are activated at the time when correction efficiency is higher, especially in the ballistic ascending segment.

To sum up, the firing time control algorithm can be improved as the following equation:

$$
\begin{aligned}
t-t^{*} & >\Delta t_{\text {fire }}, \\
A M(t) & <A M\left(t_{k}\right) \quad t<t_{k}, \\
A M(t) & <O M(t) \quad t \geq t_{k} .
\end{aligned}
$$

In (13), $t_{k}$ is the time of ballistic vertex.

\section{Results and Discussion}

To investigate the correction performance of impulse thrusters and verify the effectiveness of the firing control scheme, some simulations of a rocket have been done by numerical integration of the equations described above using a fourthorder Runge-Kutta algorithm. The rocket configuration used in the simulation study is a representative $122 \mathrm{~mm}$ artillery rocket, $2.99 \mathrm{~m}$ long, fin-stabilized, with four pop-out fins on its rear part. The main rocket motor burns for $2.55 \mathrm{~s}$ and imparts an impulse of 54247 N-s to the rocket. During the main rocket motor burns, the forward velocity of the rocket is increased from $46.9 \mathrm{~m} / \mathrm{s}$ to $935.7 \mathrm{~m} / \mathrm{s}$. The rocket weight, mass center location from the nose tip, roll inertia, and pitch inertia before and after burn is $66.1 / 43.0 \mathrm{~kg}, 1.43 / 1.21 \mathrm{~m}$, $0.16 / 0.12 \mathrm{~kg}-\mathrm{m}^{2}$, and $48.42 / 36.36 \mathrm{~kg}-\mathrm{m}^{2}$, respectively. The rocket is launched at sea level toward a target on the ground with altitude and cross range equal to zero at a range of $28000 \mathrm{~m}$. The thruster ring is assumed to be located at $0.869 \mathrm{~m}$ from the nose tip of the rocket and contains 50 individual thrusters where each individual thruster imparts an impulse of $15 \mathrm{~N}$-s on the rocket body over a time duration of $0.02 \mathrm{~s}$. The minimum firing interval of thrusters $\Delta t_{\text {fire }}$ is set to $0.2 \mathrm{~s}$. The desired activation threshold $\varepsilon$ is set to $3 \mathrm{deg}$.

The time-varying data of uncontrolled and controlled trajectories with optimum firing control scheme against a nominal command trajectory for the example rocket are compared in Figure 8.

Figure 8(a) plots the total number of thrusters fired versus time. Five thrusters are fired in 10 15s, and 43 thrusters are fired in $45 \sim 70 \mathrm{~s}$. No thrusters are fired in $15 \sim 45 \mathrm{~s}$ which indicates that the correction efficiency is relatively low during this period. No thrusters are fired after $70 \mathrm{~s}$ because the predicted impact point deviation is too small to implement any trajectory correction. The activation of thrusters will arouse the increase of attack angle of rocket, as shown in Figure 8(b).

It can be known from Figures 8(c) and 8(d) that the predicted longitudinal and horizontal impact point deviations reduce gradually. The horizontal impact point deviation reduces quickly, while longitudinal impact point deviation has no significant change in 10 20 s, which indicates that the thrusters fired in this period are mainly used for horizontal correction, corresponding to the fact that the horizontal correction efficiency of thrusters in this period is higher $\left(k_{z}\right.$ is greater, referencing to Figure 6). Both horizontal and longitudinal impact point deviations reduce quickly in 45 $70 \mathrm{~s}$, which indicates that thrusters fired in this period are used for both horizontal and longitudinal correction, corresponding to the fact that the horizontal and longitudinal correction efficiency in this period is $\operatorname{similar}\left(k_{x} \approx k_{z}\right)$.

Figures $8(\mathrm{e})$ and $8(\mathrm{f})$ show that the trajectory correction rocket flights to target point gradually under the effect of thrusters. The final impact point deviation of the rocket was reduced from horizontal $341.3 \mathrm{~m}$ and longitudinal $483.3 \mathrm{~m}$ in the uncontrolled case to horizontal $10.9 \mathrm{~m}$ and longitudinal $15.9 \mathrm{~m}$ in the controlled case, which demonstrates that the firing control scheme works effectively. 


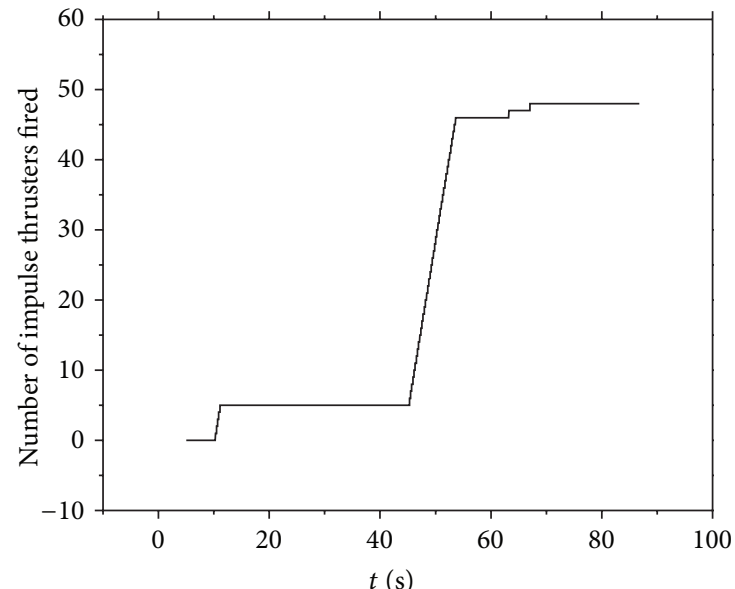

(a) Total number of thrusters tired versus time

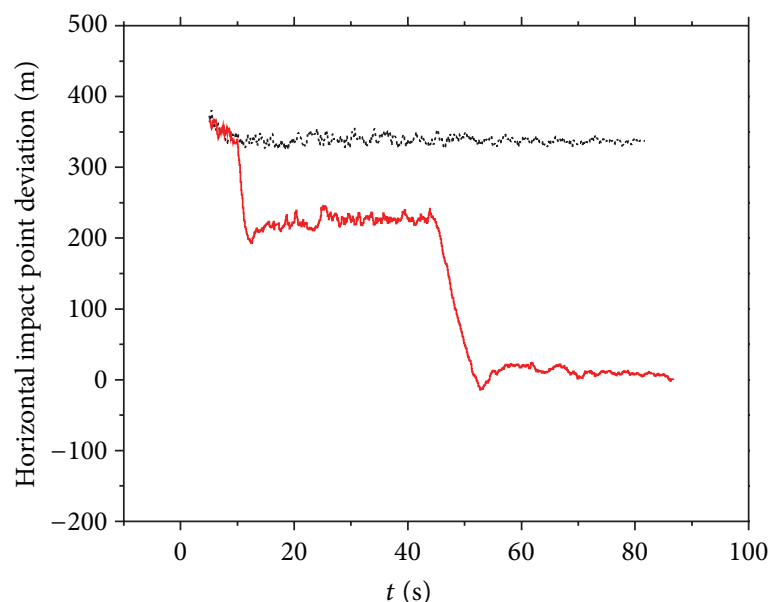

(c) Horizontal impact point deviation versus time

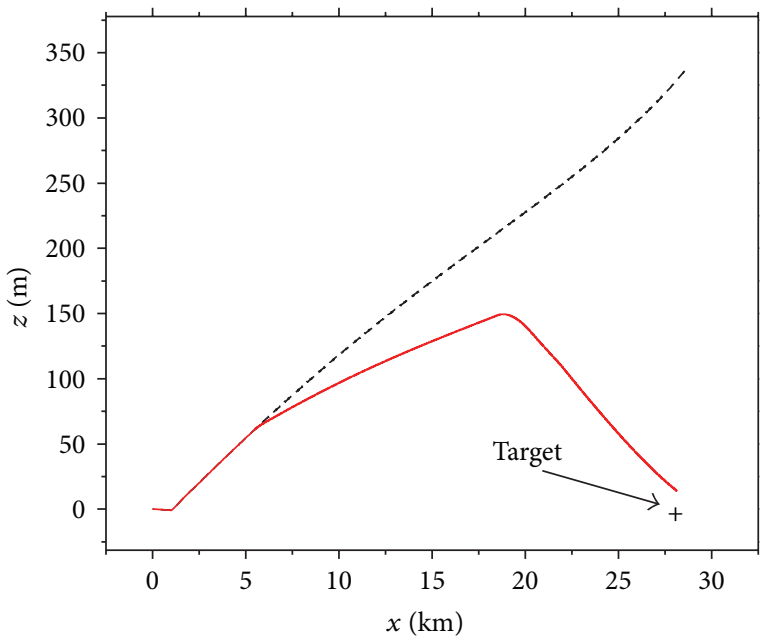

..... Uncontrolled

— Controlled

(e) Cross range versus range

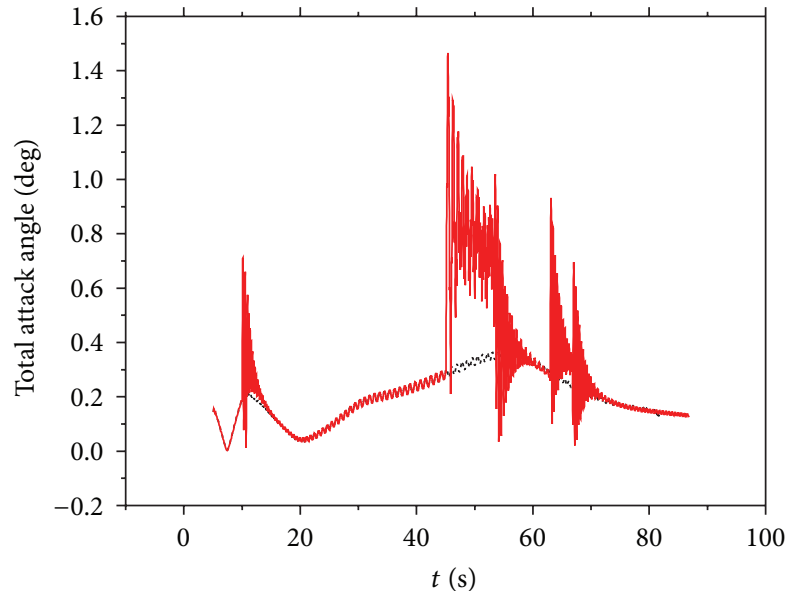

(b) Total attack angle versus time

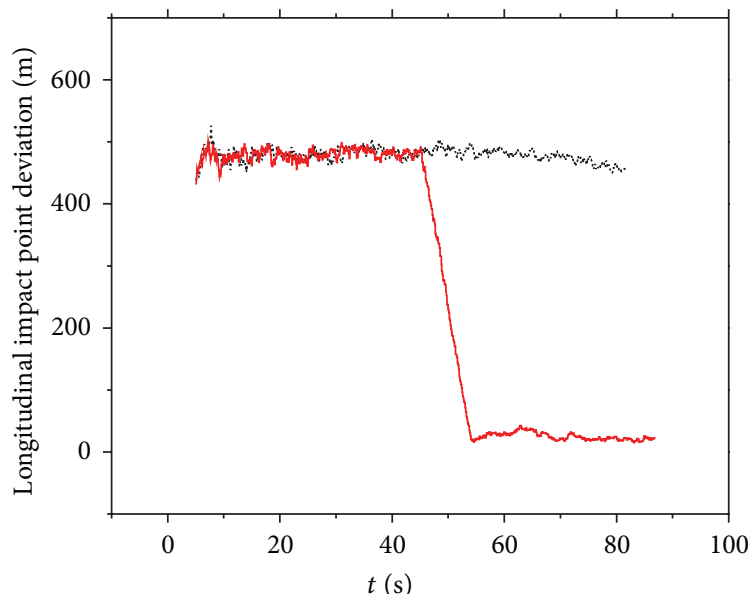

(d) Longitudinal impact point deviation versus time

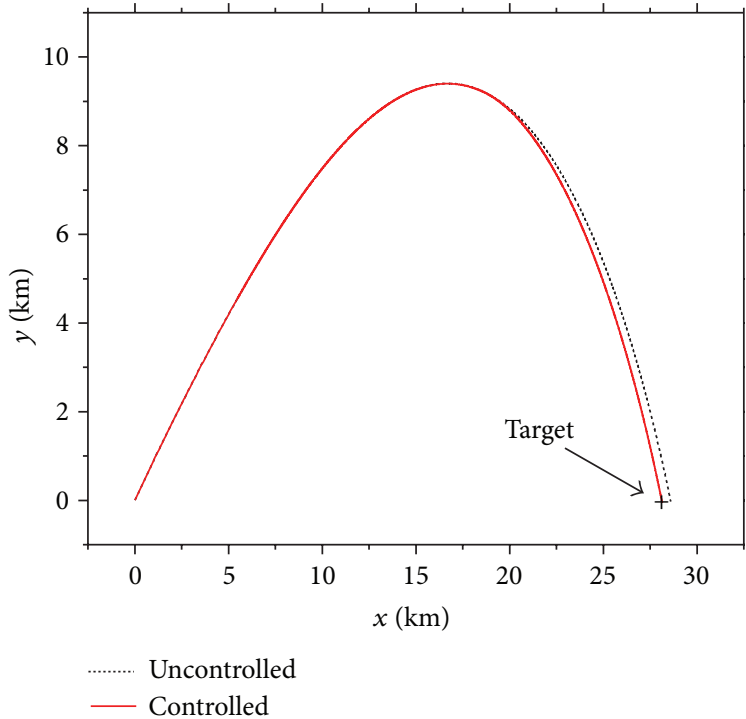

(f) Attitude versus range

FIGURE 8: Correction performance of the optimum firing control scheme. 


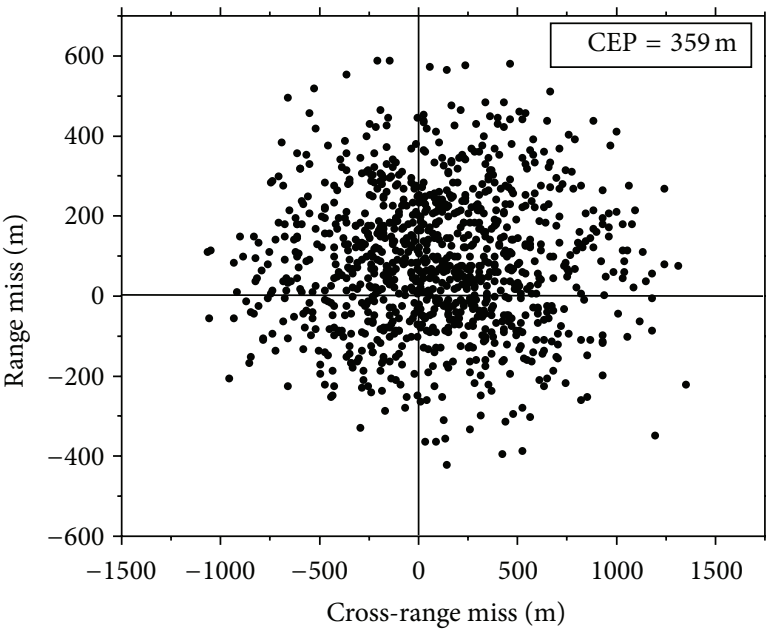

(a) Impact point distribution of uncontrolled rockets

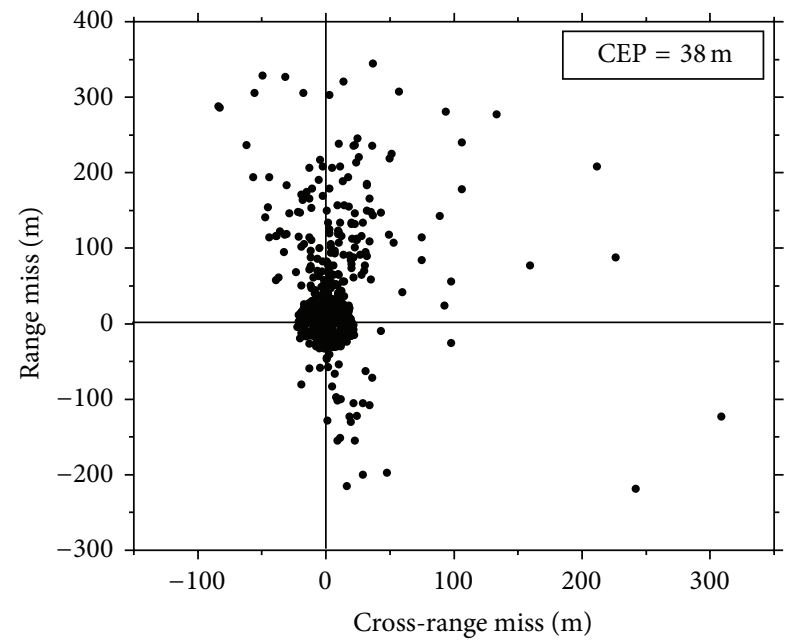

(b) Impact point distribution of rockets with general firing control scheme

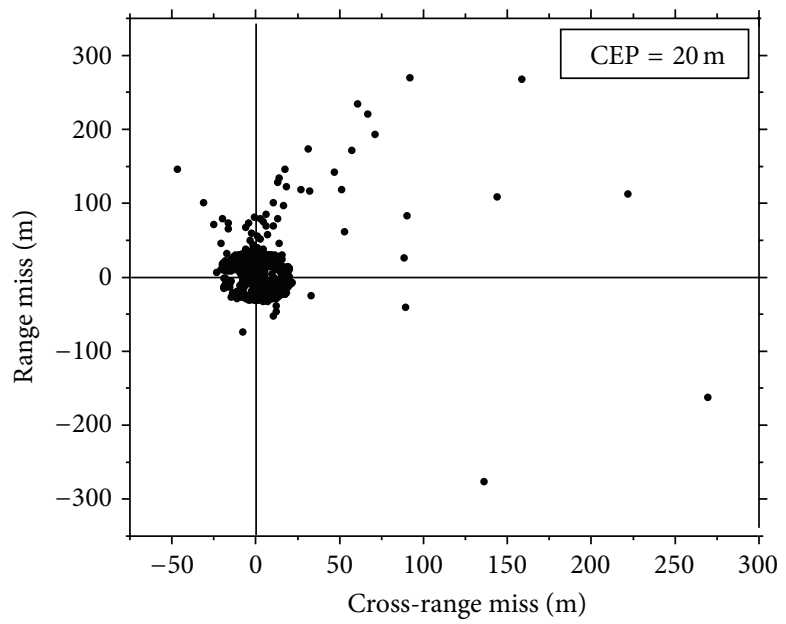

(c) Impact point distribution of rockets with the optimum firing control scheme

FIGURE 9: Impact point distribution.

Figure 9 shows the impact point distribution using the Monte Carlo method. The cases of the uncontrolled rockets as well as of the rockets with general firing control scheme and optimum firing control scheme are shown. The analysis was performed for a statistical sample of 1024 simulations. All initial conditions were modeled as Gaussian random variables, with mean values and standard deviations given in Table 1 . Wind direction is a uniform random variable between 0 and $2 \pi$. The nominal launching elevation angle is $42.31 \mathrm{deg}$, but the mean value of launching elevation angle is set as $42.51 \mathrm{deg}$, a launching elevation angle error about $0.2 \mathrm{deg}$ and a launching azimuth angle error about $0.1 \mathrm{deg}$ were introduced to simulate the accuracy errors of rockets.

The result of Monte Carlo simulations is shown in Figure 9, for uncontrolled rockets; the max value of range miss is $589.2 \mathrm{~m}$, while the min value of range miss is -421.9 , the mean value of range miss is 95.5 , the max value of cross range miss is 1349.8 , while the min value of cross range
TABLE 1: Initial conditions and disturbances.

\begin{tabular}{lccc}
\hline Parameter & Unit & Mean value & Standard deviation \\
\hline $\begin{array}{l}\text { Launching elevation } \\
\text { angle }\end{array}$ & $\mathrm{deg}$ & 42.51 & 0.2 \\
$\begin{array}{l}\text { Launching azimuth } \\
\text { angle }\end{array}$ & $\mathrm{deg}$ & 0.1 & 0.2 \\
$\begin{array}{l}\text { Impulse of the main } \\
\text { rocket motor }\end{array}$ & $\%$ & 100 & 0.1 \\
Wind & $\mathrm{m} / \mathrm{s}$ & 0 & 2 \\
\hline
\end{tabular}

miss is -1063.6 , the mean value of cross range miss is 43.8 , there are more points in the first quadrant (right upper side) of the plane coordinate system, as shown in Figure 9(a), and the CEP of uncontrolled rockets is $359 \mathrm{~m}$. Impact point distribution of the trajectory correction rockets reduces greatly, as shown in Figures 9(b) and 9(c). The rockets with 


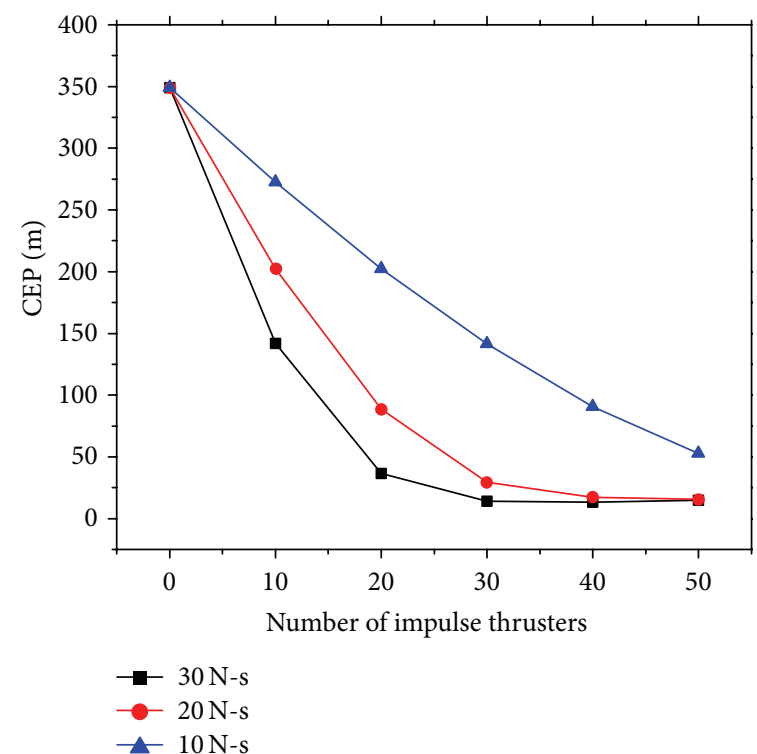

(a) CEP versus number of thrusters and individual thruster impulse

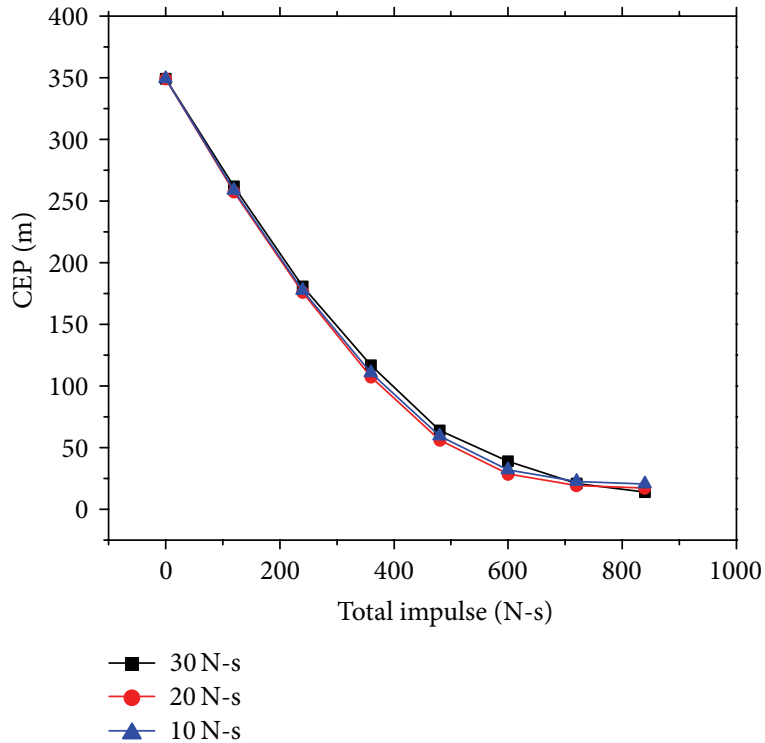

(b) CEP versus total impulse of thrusters and individual thruster impulse

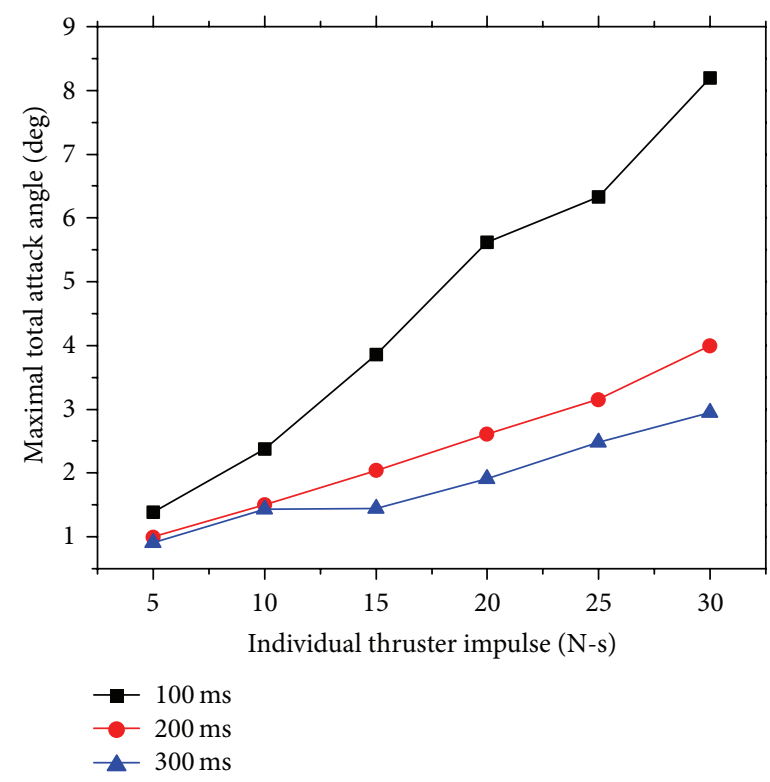

(c) Maximal total attack angle versus individual thruster impulse and minimum firing interval

FIGURE 10: The impact of parameters of thrusters on CEP and flight stability of rockets.

the general firing control scheme have a CEP of $38 \mathrm{~m}$, while the CEP of rockets with the optimum firing control scheme is $20 \mathrm{~m}$. The average thruster consumption and its standard deviation of the rockets with the general firing control scheme are 31.7 and 15.5, while the average thruster consumption and its standard deviation of the rockets with the optimum firing control scheme are 25.1 and 13.3. The decrease of impact point dispersion of rockets and the reduction of thruster consumption testify the effectiveness of firing control optimization.

Figure 10 shows the impact of thruster parameters on the CEP and flight stability of rockets. Figure 10(a) shows the relation between CEP of rockets, number of thrusters mounted on rocket, and individual thruster impulse. It can be known that the CEP of rockets is highly correlated with the number of thrusters and individual thruster impulse, and CEP reduces steadily as the number of thrusters or individual thruster impulse is increased.

Figure 10(b) shows the relationship between CEP of rockets, individual thruster impulse, and the total impulse of thrusters. For a value of the total impulse, as the individual thruster impulse is increased, the number of thrusters decreases proportionally for the total impulse to remain as 


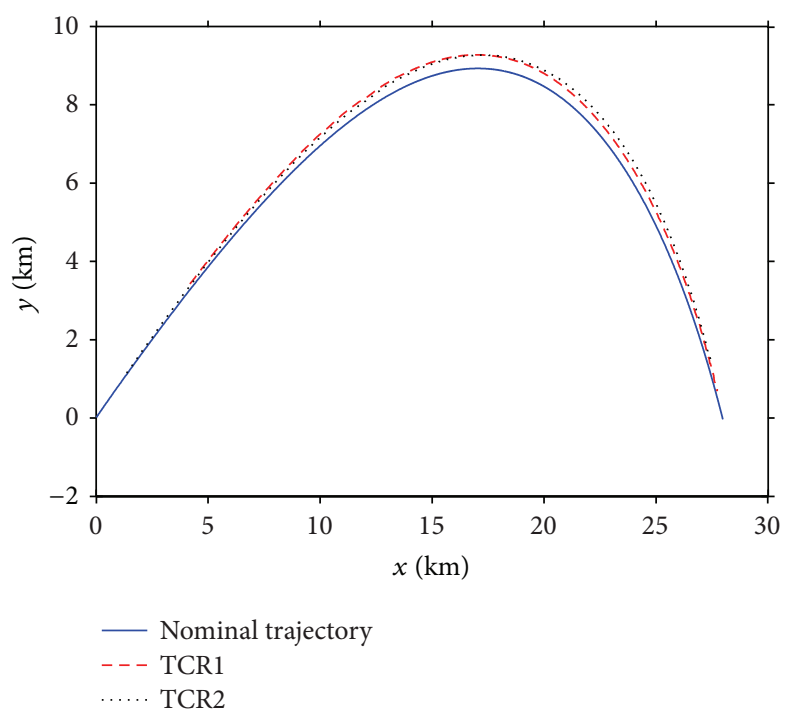

(a) Attitude versus range

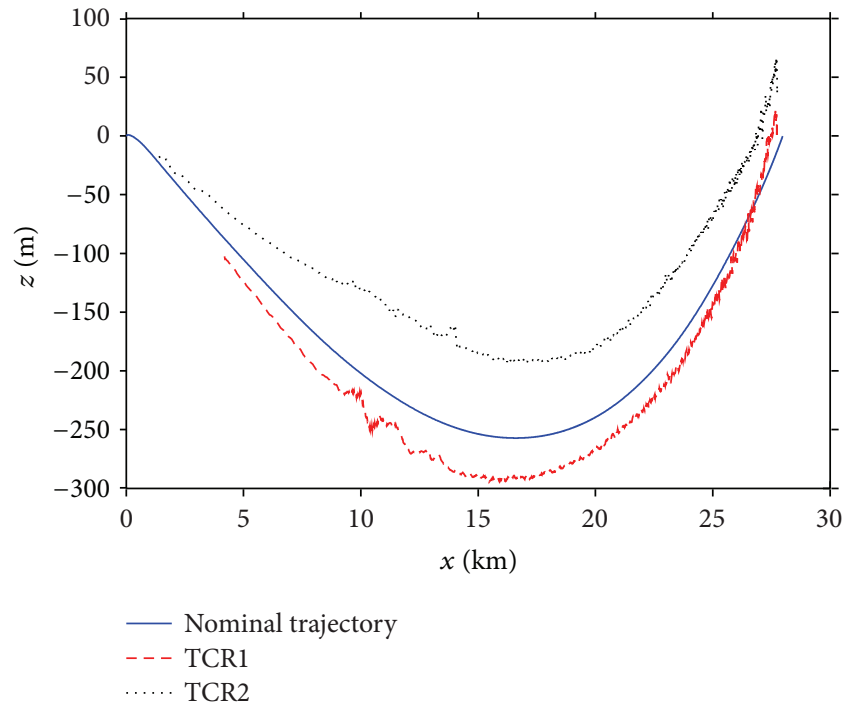

(b) Cross range versus range

FIGURE 11: The trajectory of two TCRs.

a constant. As shown in Figure 10(b), the evolution of the three curves is similar; when the thruster impulse is small, the number of thrusters is large, and some thrusters will be activated at time when the correction efficiency is lower, which is the unfavorable aspect for trajectory correction; however, large thruster number means more correction opportunity, and the correction precision of a small thruster impulse is higher, which is the favorable aspect for trajectory correction; these two aspects are contradictory, the combined effect of these two aspects leads to the similar evolution of the three curves. The result indicates that CEP is mainly influenced by the total impulse when the individual thruster impulse is reasonable, CEP reduces gradually as the total impulse is increased, and the value of individual thruster impulse has a small impact on CEP.

Figure 10(c) shows the relationship between maximum total attack angle, individual thruster impulse, and the minimum firing interval $\left(\Delta t_{\text {fire }}\right)$. The results indicate that individual thruster impulse and minimum firing interval have a direct impact on the maximum total attack angle; as individual thruster impulse increases or minimum firing interval reduces, the maximum total attack angle increases, which may affect the flight stability of trajectory correction rockets.

Based on the above discussion, some suggestions are put forward to determine the thruster configuration parameters of trajectory correction rockets. Firstly, the total impulse should be determined according to CEP needed, because the impact point dispersion is mainly influenced by the total impulse of lateral thrusters deployed. Secondly, individual thruster impulse should be determined according to the total impulse, limits of layout space on the rocket, flight stability of rockets, cost, and so forth. If the individual thruster impulse is too small, there may be too many thrusters needed to be mounted on the rocket. On the other hand, if the individual thruster impulse is too large, the flight stability may deteriorate. Thirdly, the minimum firing interval should be determined according to the individual thruster impulse, flight stability of rockets, correction efficiency of thrusters, and so forth. If the individual thruster impulse is large, a relatively large minimum firing interval should be set to guarantee the flight stability of rockets. If the individual thruster impulse is small, a relatively small minimum firing interval time should be set to insure thrusters can be activated at the segment of trajectory while the correction efficiency is higher.

Live experiments have been done to verify the effectiveness of the firing control scheme. The characters of the trajectory correction rockets (TCR) have been launched same as the rocket described in simulations above. Two TCRs have been launched, toward a target on the ground with altitude equal to $200 \mathrm{~m}$ and cross range equal to zero at a range of $28000 \mathrm{~m}$; the launching elevation angle was set to $43.6 \mathrm{deg}$, according to the weather of the time. Figure 11 shows the trajectory of two TCRs contrasted with the nominal trajectory. As shown in Figure 11(a), at the ballistic vertex, the attitude of two TCRs is 300 400 $\mathrm{m}$ higher than the nominal trajectory; then the trajectory of two TCRs gradually close to the nominal trajectory under the effect of flight control system. As shown in Figure 11(b), the cross range of the two TCRs gradually closes to the nominal trajectory under the effect of flight control system. The final impact point deviation of TCR1 is $(4.5,21.2)$ and the final impact point deviation of TCR2 is $(-28.3,35.4)$, which demonstrates the firing control scheme works effectively.

\section{Conclusion}

This paper establishes the 6-DOF trajectory model of a rocket with lateral force and presents an optimum control scheme of firing time and firing phase angle by taking impact point 
deviation as optimum objective function which takes account of the difference of longitudinal and horizontal correction efficiency, firing delay, roll rate, flight stability, and so forth. The result of Monte Carlo simulations shows that the uncontrolled rockets have a CEP of $359 \mathrm{~m}$; the CEP was improved to $38 \mathrm{~m}$ with the general firing control scheme; as a contrast, the CEP was improved to $20 \mathrm{~m}$ with the optimum firing control scheme. The average thruster consumption and its standard deviation of the rockets with the general firing control scheme are 31.7 and 15.5, while the average thruster consumption and its standard deviation of the rockets with the optimum firing control scheme are 25.1 and 13.3. The decrease of CEP and the reduction of thruster consumption testify the effectiveness of firing control optimization. The variations of rocket impact point dispersion are analyzed with different impulse and number of impulse thrusters. It is shown that the impact point dispersion is mainly influenced by the total impulse of impulse thrusters deployed and steadily decreases as the total impulse is increased. The impulse, number, and firing interval need to be optimized to insure the flight stability of rockets and impulse thrusters activated at time when the correction efficiency is higher. Two trajectory correction rockets have been launched to verify the effectiveness of the firing control scheme; the final impact point deviations of two trajectory correction rockets are, respectively, $(4.5,21.2)$ and $(-28.3,35.4)$, which demonstrates the firing control scheme works effectively.

\section{Conflict of Interests}

The authors declare that there is no conflict of interests regarding the publication of this paper.

\section{References}

[1] M. Costello, "Extended range of a gun launched smart projectile using controllable canards," Shock and Vibration, vol. 8, no. 3-4, pp. 203-213, 2001.

[2] J. Rogers and M. Costello, "Design of a roll-stabilized mortar projectile with reciprocating canards," Journal of Guidance, Control, and Dynamics, vol. 33, no. 4, pp. 1026-1034, 2010.

[3] G. Cooper, F. Fresconi, and M. Costello, "Flight stability of an asymmetric projectile with activating canards," Journal of Spacecraft and Rockets, vol. 49, no. 1, pp. 130-135, 2012.

[4] M. Costello and A. Peterson, "Linear theory of a dual-spin projectile in atmospheric flight," Journal of Guidance, Control, and Dynamics, vol. 23, no. 5, pp. 789-797, 2000.

[5] A. Elsaadany and Y. Wen-Jun, "Accuracy improvement capability of advanced projectile based on course correction fuze concept," The Scientific World Journal, vol. 2014, Article ID 273450, 10 pages, 2014.

[6] M. Amitay, D. R. Smith, V. Kibens, D. E. Parekh, and A. Glezer, "Aerodynamic flow control over an unconventional airfoil using synthetic jet actuators," AIAA journal, vol. 39, no. 3, pp. 361-370, 2001.

[7] M. S. L. Hollis and F. J. Brandon, "Range correction module for a spin stabilized projectile," U.S. Patent Documents US-5816531, 1998.
[8] M. S. L. Hollis and F. J. Brandon, "Design and analysis of a fuze-configurable range correction device for an artillery projectile," Report ARL-TR-2074, U.S. Army Research Laboratory, Aberdeen Proving Ground, Aberdeen, Md, USA, 1999.

[9] J. Brandeis and J. Gill, "Experimental investigation of super- and hypersonic jet interaction on missile configurations," Journal of Spacecraft and Rockets, vol. 35, no. 3, pp. 296-302, 1998.

[10] B. Burchett, A. Peterson, and M. Costello, "Prediction of swerving motion of a dual-spin projectile with lateral pulse jets in atmospheric flight," Mathematical and Computer Modelling, vol. 35, no. 7-8, pp. 821-834, 2002.

[11] D. Corriveau, P. Wey, and C. Berner, "Thrusters pairing guidelines for trajectory corrections of projectiles," Journal of Guidance, Control, and Dynamics, vol. 34, no. 4, pp. 1120-1128, 2011.

[12] T. Harkins and T. Brown, "Using active damping as a precisionenhancing technology for 2.75-inch rockets," Tech. Rep. ARLTR-1772, U.S. Army Research Laboratory, Aberdeen, Md, USA, 1999.

[13] T. Jitpraphai and M. Costello, "Dispersion reduction of a direct fire rocket using lateral pulse jets," Journal of Spacecraft and Rockets, vol. 38, no. 6, pp. 929-936, 2001.

[14] B. Burchett and M. Costello, "Model predictive lateral pulse jet control of an atmospheric rocket," Journal of Guidance, Control, and Dynamics, vol. 25, no. 5, pp. 860-867, 2002.

[15] S. K. Gupta, S. Saxena, A. Singhal, and A. K. Ghosh, “Trajectory correction flight control system using pulsejet on an artillery rocket," Defence Science Journal, vol. 58, no. 1, pp. 15-33, 2008.

[16] B. Pavkovic, M. Pavic, and D. Cuk, "Frequency-modulated pulse-jet control of an artillery rocket," Journal of Spacecraft and Rockets, vol. 49, no. 2, pp. 286-294, 2012.

[17] B. Pavkovic, M. Pavic, and D. Cuk, "Enhancing the precision of artillery rockets using pulsejet control systems with active damping," Scientific Technical Review, vol. 62, no. 2, pp. 10-19, 2012.

[18] H.-W. Yang, L.-H. Dou, and M.-G. Gan, "Control method of impulse actuator of antiaircraft trajectory correction projectile," Transaction of Beijing Institute of Technology, vol. 31, no. 10, pp. 1184-1188, 2011.

[19] Y.-J. Cao, S.-X. Yang, and X.-J. Li, "Research on firing phase angle optimization of terminal trajectory correction projectile based on pulse jet control," Acta Armamentarii, vol. 29, no. 8, pp. 897-901, 2008.

[20] F. Gao and H. Zhang, "Study of 2-D trajectory correction based on geomagnetic detection with impulse force for projectiles," Journal of System Simulation, vol. 23, no. 1, pp. 123-128, 2011.

[21] X. Qian, R. Lin, and Y. Zhao, Aerothermodynamics of Missile Flight, Beijing Institute of Technology Press, Beijing, China, 2008. 

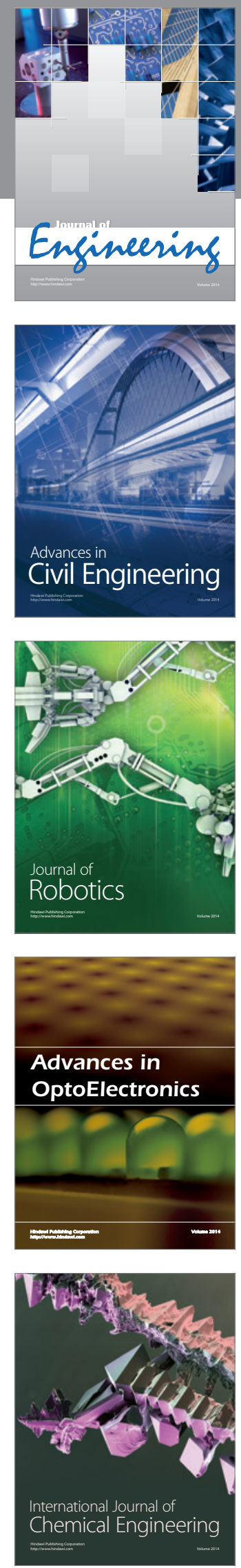

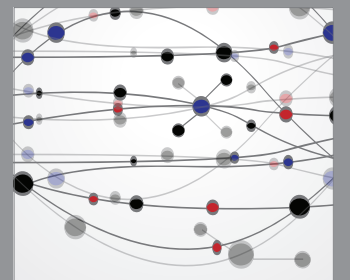

The Scientific World Journal
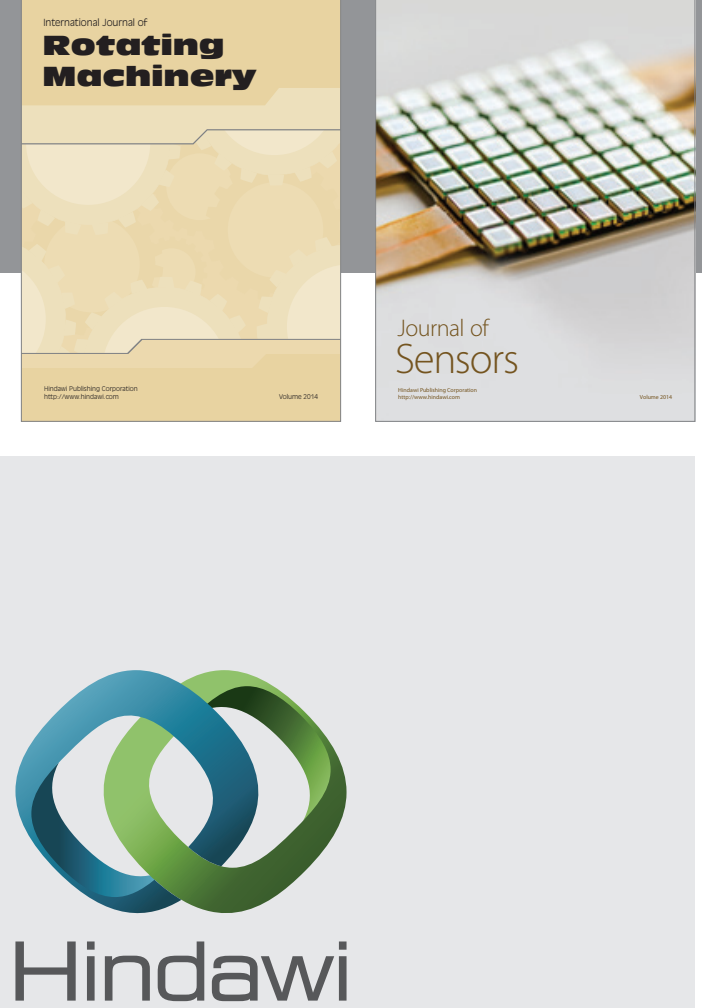

Submit your manuscripts at http://www.hindawi.com
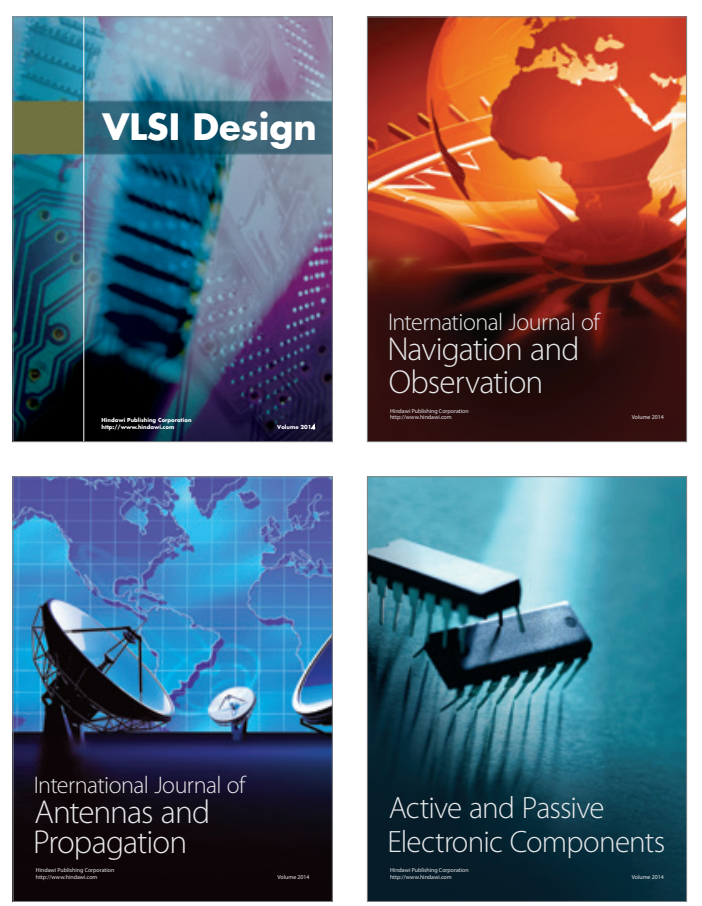
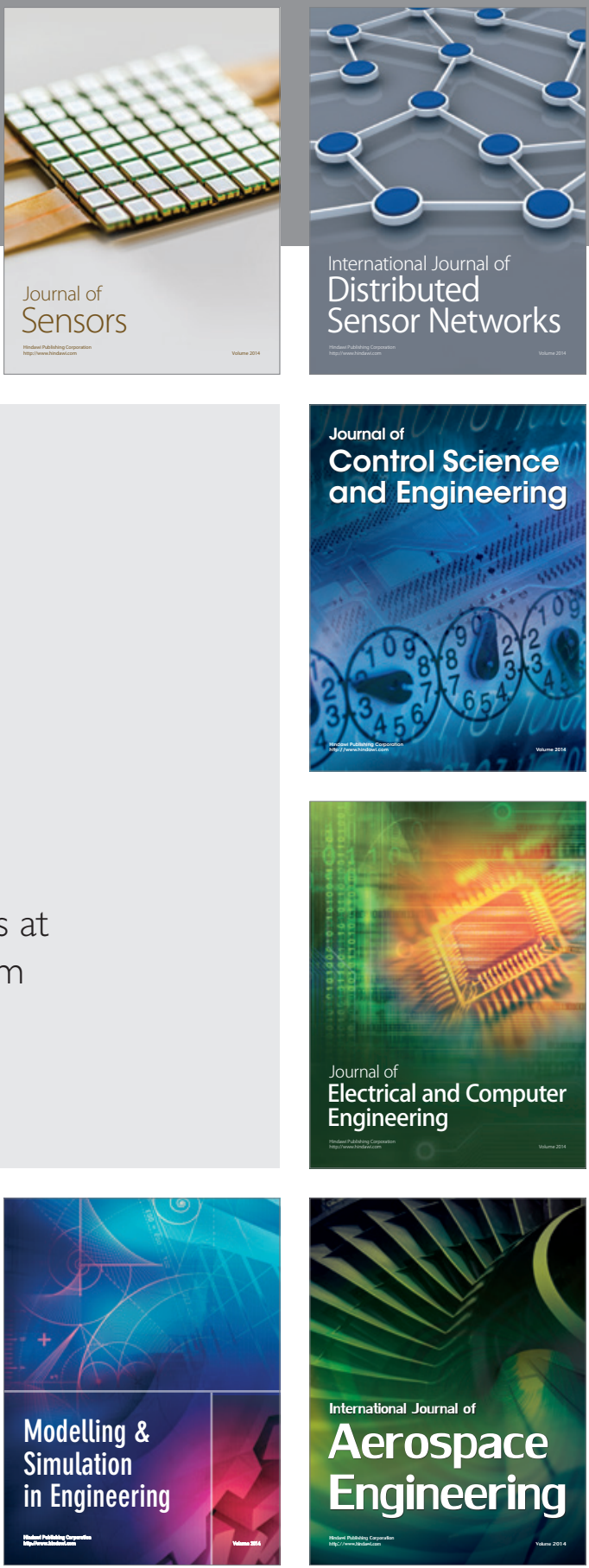

Journal of

Control Science

and Engineering
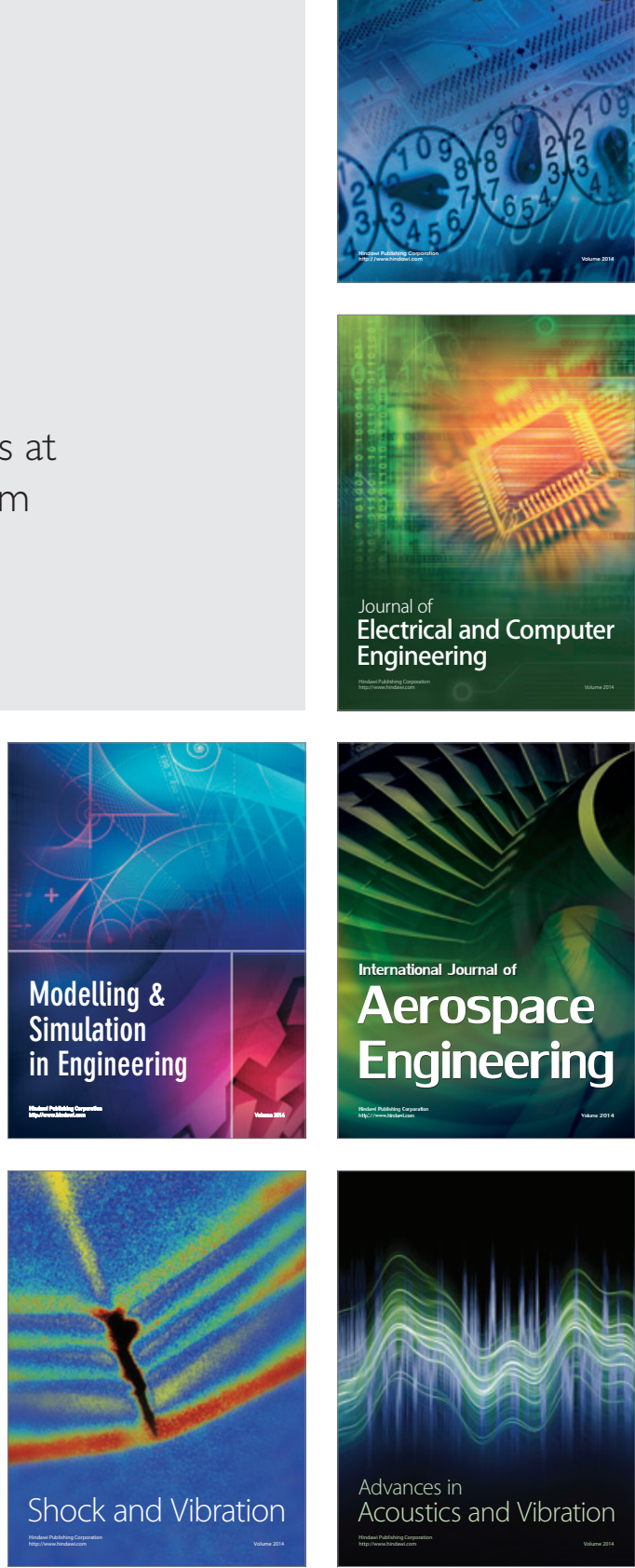